\title{
Interactive comment on "Drainage of organic soils and GHG emissions: Validation with country data" by Giulia Conchedda and Francesco N. Tubiello
}

\section{Anonymous Referee \#2}

Received and published: 8 September 2020

This study is highly valuable and timely in the context of GHG mitigation strategies and country submissions and reporting under UNFCCC and commitments to the Paris Agreement. Currently FAO is the only global consistent database providing information on activity data, emission factors and GHG emissions from drained organic soils, and not only. The authors update the old static map of drained organic soils from the year 2000 and their CO2/N2O emissions with a new methodology developed for FAOSTAT which includes dynamic maps. The authors present times series of global annual dataset of drained area and CO2/N2O emissions between 1990 - 2019 and validate it with country information. Some uncertainty information is provided but would be very useful if uncertainties on emissions could be quantified. I would also encourage in the future updates, the use of more recent land use and land use change products 
(e.g. HILDA+) (https://landchange.imk-ifu.kit.edu/news/sneak-preview-hilda-coming ). Paper reads well but I would suggest to be read by a native speaker to help improving its flow. Similar to reviewer \#1, I agree to its publication after minor/technical revisions.

Specific technical comments: Line 31: ...large quantities of available organic substrate. Line 32: replace "and especially since 1990" with "the world, especially after the 90s..." and perhaps add in brackets where oil palm became permanent crop Line 45: to be clear if wetland condition or wet condition. Agree with referee \#1: add references not only for boreal but also for alpine organic soils (bogs, fens) Line 48: delete indeed Line 56: as "as they continue emitting.." Lines 74-76: I would reference or name in brackets all the maps used in this study (land use, density etc.) when they appear for the first time Line 105: delete "indeed be" Line 139: how about other species? I guess for the boreal areas with organic soils other animals are present - e.g. reindeers? Line 144: which map did you use from the JRC? Please reference/name the original map as well. Line 154: please reference the Climate Convention Line 167: you mention here drained peats: is it only peat or drained organic soils in general? Line 178: "data suggests" Line 182: To which period are you referring to about Asia drainage (30\%)? Over the whole studied period or one particular year? Line 191: If $833 \mathrm{Mt}$ refers here to 2019 then I would reformulate: "In 2019, global GHG emissions from drained organic soils were $833 \mathrm{Mt}$ CO2eq. They were $13 \%$ and $10 \%$ higher when compared to 1990 and 2000 respectively, representing $8 \% \ldots$... Line 194 and 195: I would delete gas. Are the global emissions/all emissions you refer here total GHG emissions in $\mathrm{CO} 2$ or CO2eq or total emissions from drainage? Please explain. Lines 211-215: I would add to table 5 all specific comparisons. I was also wondering why you are using the old reference of Joosten 2002 and not a more recent updated information from his peatland database which I think Prof. Joosten is updating regularly for the areas and emissions from organic soils. (https://greifswaldmoor.de/global-peatland-database-en.html) Line 227: countries from South and Central America Lines 235-240: do you know what causes the main difference between the way Gumbricht, Page and FAOSTAT calculate country level estimates? Are these uncertainties due to area, method, level of detail

Interactive comment
Printer-friendly version

Discussion paper 
or input to the maps? Perhaps add a sentence at the end of the paragraph summarizing these differences. Line 247: please specify which UNFCCC data was used? 2019, 2020? Same for line 252: UNFCCC (year) data are available. . Lines 262: do you know why these differences? I think it should be mentioned that Canada uses a high Tier model (CBM) to report to the UNFCCC. Line 266: I would name LULUCF sector and not category. As you define further, categories are 4.B, 4.C etc. Line 270: higher Tiers than... Line 271: delete As Line 282: please reference the IPCC Wetlands EFs, are the values from the Wetlands Supplement or the IPCC 2006 chapter 7? Line 295: delete the in "vs the 304". Please add everywhere the year for the UNFCCC data. Line 309: to those from established or better peer-reviewed literature Line 311: please check references: Petersen or Peterson Line 318: which emissions (CO2, $\mathrm{N} 2 \mathrm{O}$, total?) in this country? Emissions were due to.. Please add a \% in brackets. Line 320: may less. ... please complete: may be less or may not be less important. . Line 322: are direct measurements the in-situ measurements? And typically analyse.. Line 336: available Line 339: million tonnes, be consistent until now Mt was used Line 351: consistent with writing IPCC Figures 11 and 13: why the use of both gigagrams and $\mathrm{kt}$ ?

Interactive comment on Earth Syst. Sci. Data Discuss., https://doi.org/10.5194/essd-2020-202, 2020. 